\title{
Membangun Keluarga Cerdas Obat Dengan Edutoys
}

\author{
Dyani Primasari Sukamdi, Mega Octavia ${ }^{2}$, dan Indriastuti Cahyaningsih ${ }^{3}$ \\ 1. Program Studi Farmasi, Fakultas Kedokteran dan Ilmu Kesehatan, Universitas Muhammadiyah Yogyakarta, Bantul, Yogyakarta 55183 \\ Email: dyani.primasari@gmail.com \\ DOI: $10.18196 / p p m .32 .183$
}

\begin{abstract}
Abstrak
Kelvarga merupakan lingkup organisasi terkecil. Kelvarga menjadi tempat belajar pertama bagi anak-anak. Kebiasaan baik dalam kelvarga merupakan fondasi kuat bagi anak untuk mempraktikkannya di sekolah. Salah satu kebiasaan baik dalam kelvarga adalah tepatnya pengelolaan obat keluarga. Pembiasaan baik untuk anak dapat dilakukan dengan metode belajar yang tepat. Kebiasaan baik yang berasal dari rumah akan menjadi fondasi baik bagi proses belajar di TK Al Fatah Sedan. Penyuluhan ini bertujuan untuk mengenalkan kebiasaan baik dalam pengelolaan obat dengan metode yang tepat kepada anak-anak. Metode tersebut adalah metode Montessori. Penyuluhan dilakukan secara daring dengan dua topik utama: "Dagusibu-Gerakan Keluarga Sadar Obat" dan "Bagaimana Memulai Montessori dari Rumah?". "Penyuluhan DagusibuGerakan Keluarga Sadar Obat" berisi cara pengelolaan obat dalam keluarga, sedangkan topik kedua, yaitu "Bagaimana Memulai Montessori dari Rumah?" berisi pengetahuan mengenai metode Montessori untuk diterapkan di rumah. Penyuluhan diikuti oleh 35 orang wali murid dan 17 orang guru. Selama penyuluhan diberikan kuesioner kepada peserta. Dari 52 orang peserta, sebanyak 25 orang telah mengisi kuisioner. Dari 25 orang, didapatkan hasil bahwa 88\% mengakui bahwa sebelum penyuluhan pernah mendengar istilah dagusibu. Pembelian obat selalu di apotek dilakukan oleh $76 \%$ peserta. Menggunakan obat sesuai ketentuan dilakukan oleh 60\% peserta. Untuk pengetahuan bahwa jika obat terkena sinar matahari langsung, udara lembab, suhu ekstrim dan goncangan fisik, obat akan cepat rusak, telah diketahui oleh 96\% peserta. Dalam keluarga, sebanyak $92 \%$ peserta mengajari anak untuk mengelola obat. Berdasarkan data tersebut, dapat diketahui bahwa pengetahuan tentang pengelolaan obat kepada masyarakat telah banyak diketahui dan diajarkan pada anak usia dini di rumah.
\end{abstract}

Kata Kunci: Dagusibu, Montessori, Keluarga, Pengelolaan Obat

\section{Pendahuluan}

Salah satu permasalahan kesehatan yang terjadi di sekolah adalah seringnya penularan penyakit flu dan batuk pada murid TK Al Fatah. Hal ini kemungkinan diakibatkan oleh kurangnya pengetahuan murid akan kesehatan dan kebersihan diri. Pengetahuan anak akan kebersihan dan kesehatan diri sebaiknya dimulai dari lingkup terkecil, yaitu keluarga di rumah. Pemahaman akan pentinya menjaga kebersihan diri sebagai salah satu faktor timbul/ tidaknya penyakit belum dilakukan oleh masing-masing keluarga. Selain itu, permasalahan yang sering terjadi di TK Al Fatah adalah kurangnya pengetahuan tentang obat dan cara pengelolaannya. Tujuan pengelolaan obat adalah tersedianya obat saat dibutuhkan. Ketersediaan obat meliputi jenis, jumlah, dan kualitas secara efisien. Pengelolaan obat dapat dipakai sebagai proses penggerak dan pemberdayaan semua sumber daya yang dimiliki untuk dimanfaatkan dalam mewujudkan ketersediaan obat pada saat dibutuhkan. Hal ini dilakukan agar operasional efektif dan efisien (Direktur Bina Obat Publik dan Perbekalan Kesehatan, 2007). Pengelolaan obat biasa dikenal dengan program dagusibu (dapatkan, gunakan, simpan, dan buang). Program ini telah dikenalkan kepada banyak lapisan masyarakat untuk meningkatkan kesadaran akan pentingnya mengelola obat. Namun, masih sedikit pihak yang mengenalkannya pada tingkatan keluarga dan dimulai dari anak usia dini. Pendidikan anak usia dini yang biasa dipandu oleh orang tua di rumah dapat menjadi langkah baik untuk program ini. Program ini juga dikenal dengan Gerakan Keluarga Sadar Obat (GKSO) yang bertujuan untuk memberi kesadaran pada masyarakat luas untuk dapat cerdas dan mandiri serta berperilaku sehat dan bertanggungjawab, terutama terkait dengan obat.

Taman Kanak-Kanak (TK) Al Fatah, Sedan merupakan salah satu sekolah usia dini yang terletak di Dusun Sedan, Desa Sariharjo, Kecamatan Ngaglik, Kabupaten Sleman, Yogyakarta. 
Sekolah ini berdiri pada tanggal 01 Mei 2000. Kepengurusan sekolah dilakukan oleh Yayasan Al Fatah yang beralamat sama dengan letak sekolah. Murid yang terdapat di TK Al Fatah Sedan berjumlah 143 orang yang terdiri atas 75 siswa laki-laki dan 68 siswa perempuan (Kemendikbud, 2019). Guru yang mengajar di sekolah tersebut berjumlah 12 orang. Selain itu, TK Al Fatah mempunyai 1 tenaga administrasi dan 1 penjaga sekolah. Waktu penyelenggaraan belajar-mengajar dilakukan sehari penuh selama 6 hari (Kemendikbud, 2019). TK Al Fatah Sedan mempunyai fasilitas yang terdiri atas 6 ruang kelas, 1 ruang ekstrakulikuler, kantor guru, dan ruang administrasi. Selain itu, terdapat juga halaman yang digunakan untuk ruang bermain dan beraktivitas luar oleh guru dan murid. Secara sarana dan prasarana, TK Al Fatah Sedan sudah memadai untuk proses belajar. Dalam proses belajar mengajar, guru dan wali murid belum mengenal secara detail metode Montessori yang menggunakan pendekatan kemandirian anak.

Metode Montessori adalah metode yang menggunakan cara "bermain adalah pekerjaan yang penting bagi anak usia dini” (Kusumo, 2016). Bagi Kusumo (2016). Montesorri merupakan gaya hidup yang dapat dimulai dari rumah, yakni anak diberikan kebebasan untuk eksplorasi setiap bagian dan sudut rumah dengan aman. Metode Montessori juga dapat digunakan anak untuk menambah wawasan motorik halus, motorik kasar, serta koordinasi seluruh inderanya. Metode ini cocok untuk menanamkan pentingnya pengelolaan obat di rumah untuk anak-anak.

Berdasarkan studi pendahuluan yang dilakukan terhadap permasalahan kesehatan ini, peneliti telah merumuskan kegiatan yang dapat dilaksanakan bersama dengan TK Al Fatah Sedan. Kegiatan ini bertujuan untuk mengenalkan murid, guru, dan orang tua di lingkungan TK Al Fatah terhadap pentingnya kebersihan dan kesehatan diri serta pengelolaan obat yang baik. TK Al Fatah Sedan sendiri diketahui belum pernah melakukan program pengenalan dagusibu / GKSO sebelumnya. Hal ini menjadi dasar untuk dapat mengenalkannya pada wali murid sekaligus memberi pandangan tentang metode yang tepat untuk mengarahkan anak-anak usia dini dengan metode Montesorri. Tujuan diadakannya penyuluhan ini adalah untuk mengenalkan wali murid TK Al Fatah Sedan dan masyarakat cara menanamkan pentingnya pengelolaan obat pada anak usia dini dengan metode Montessori.

\section{Metode Pelaksanaan}

Pengabdian dilaksanakan dengan penyuluhan secara daring. Pelaksanaannya pada hari Sabtu, tanggal 15 Agustus 2020 pukul 08.00-11.00 WIB dengan platform Zoom dan siaran langsung pada Youtube channel Program Studi Farmasi UMY. Sasaran peserta penyuluhan merupakan guru TK Al Fatah Sedan, wali murid TK Al Fatah Sedan, dan masyarakat. Penyuluhan dilakukan dalam dua sesi. Sesi pertama menjelaskan topik "Dagusibu-Gerakan Keluarga Sadar Obat" yang disampaikan oleh apt. Dyani Primasari Sukamdi, M.Sc, sedangkan sesi kedua menjelaskan topik "Bagaimana Memulai Montessori dari Rumah?" yang disampaikan oleh RR. Rayi Chandra Mitri, S.Pd.

Selama penyuluhan dibagikan kuisioner bagi peserta. Total peserta yang mengikuti penyuluhan adalah 35 orang wali murid, 17 orang guru, dan masyarakat. Total peserta yang mengikuti penyuluhan adalah 52 orang. Total peserta yang mengikuti penyuluhan 52 orang, terdiri atas 35 orang wali murid dan masyarakat serta 17 orang guru. Kuisioner diberikan mulai dari awal penyuluhan untuk diisi oleh setiap peserta. Kuisioner diberikan melalui google form yang berisi pertanyaan tentang pengetahuan peserta mengenai manajemen obat di rumah. 


\section{Hasil dan Pembahasan}

Penyuluhan dalam program ini dilakukan dalam dua sesi, yaitu: sesi pertama dengan topik "Dagusibu-Gerakan Keluarga Sadar Obat" disampaikan oleh apt. Dyani Primasari Sukamdi, M.Sc. Topik ini mengupas tuntas cara atau proses yang benar tentang pengelolaan obat di dalam rumah dimulai dari keluarga. Hal ini dilakukan untuk meningkatkan kesadaran masyarakat akan pentingnya kemandirian dan kecerdasan diri dalam berperilaku sehat, khususnya tentang pengelolaan obat (PP IAI, 2014). Penjelasan yang diberikan meliputi cara mendapatkan obat yang benar, menggunakan obat yang benar, menyimpan obat yang sesuai, dan membuang obat yang tepat. Menurut Direktur Bina Obat dan Publik dan Perbekalan Kesehatan (2007), pembelian obat dapat dilakukan di tempat-tempat yang telah memiliki izin, seperti apotek, toko obat berizin, rumah sakit, dan puskesmas. Dalam proses ini, ditekankan cara peserta membedakan golongan obat, yakni golongan obat yang dapat dibeli tanpa resep dan obat yang harus dibeli dengan resep (Maziyyah, 2015). Penandaan kemasan obat dan pemeriksaan kualitas obat juga harus diperhatikan saat mendapatkan obat.

Menurut Direktur Bina Obat dan Publik dan Perbekalan Kesehatan (2007), hal selanjutnya yang dapat dilakukan adalah cara menggunakan obat dengan benar, hal ini mencakup pasien dapat melihat identitas obat, kondisi obat yang didapatkan, apakah masih baik, serta diperiksa juga peringatan dalam kemasan obat dan ketentuan penggunaan obat. Penekanan yang diberikan kepada peserta pada tahap ini adalah etiket obat pada kemasan sebaiknya tidak dilepas karena memuat informasi penting mengenai cara penggunaan obat. Jika terdapat keluhan setelah menggunakan obat, seperti adanya kondisi yang tidak diinginkan muncul, pasien harus menghubungi dokter untuk berkonsultasi. Pada tahap penyimpanan obat, sangat dianjurkan melihat petunjuk penyimpanan obat pada masing-masing kemasan obat. Setelah obat selesai digunakan, proses pembuangan obat juga harus mengikuti proses-proses tertentu sesuai jenis sediaan obat (Maziyyah, 2015).

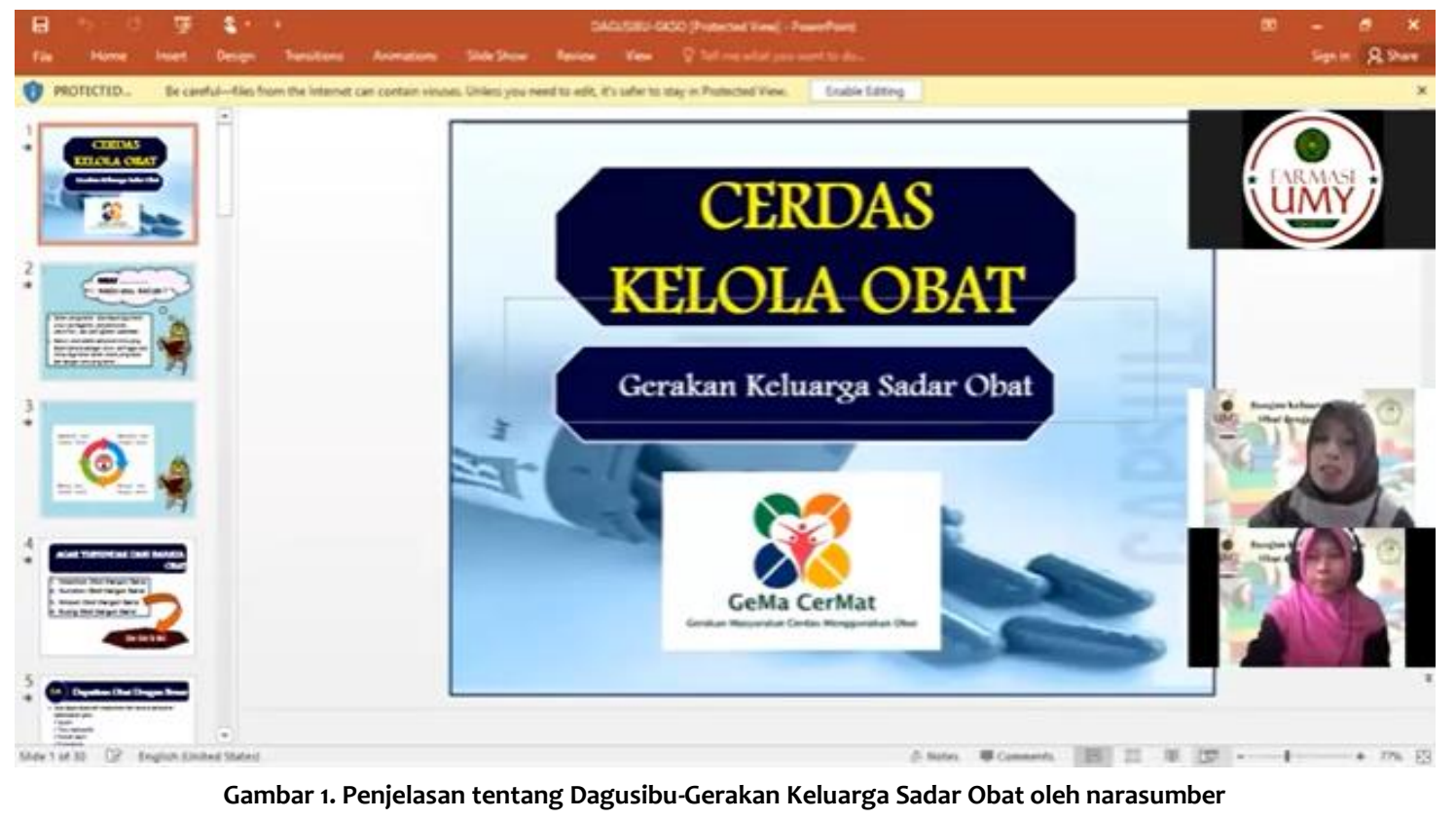

Pada sesi kedua, dijelaskan topik "Bagaimana Memulai Montessori dari Rumah?” yang disampaikan oleh RR. Rayi Chandra Mitri, S.Pd. Metode Montessori merupakan metode yang baik untuk mengenalkan kemandirian dan meningkatkan wawasan motorik pada anak usia dini. Metode ini mampu mengenalkan anak tentang kebutuhan sehari-hari yang akan ditemuinya nanti secara konkret (Kusumo, 2016). Peserta dijelaskan sejarah Montessori terlebih dahulu sebagai perkenalan. Selanjutnya, peserta diperlihatkan periode sensitif bagi anak yang terbagi 
menjadi enam periode. Periode tersebut adalah periode sensitif indera (0-5 tahun), sensitif keteraturan (0-5 tahun), sensitif benda kecil (1-3 tahun), sensitif bergerak (1-4 tahun), sensitif bergerak (0-6 tahun), dan sensitif sosial (2,5-6 tahun) (Masyrofah, 2017). Periode sensitifitas ini akan menjadi dasar bagi orang tua untuk mengenalkan jenis kegiatan yang cocok diberikan pada anak di rumah. Selain mengenali periode sensitivitas, orang tua juga perlu melakukan persiapan terhadap lingkungan. Lingkungan belajar anak harus diakomodasi sedemikian rupa agar dapat membantu anak untuk menjalankan kesehariannya dengan otomatis. Hal ini akan menumbuhkan rasa tanggung jawab dan kemandirian dalam diri anak (Kusumo, 2017). Dalam penjelasannya, narasumber juga memberikan gambara aktivitas yang dapat dilakukan oleh anak-anak terkait pengelolaan obat di rumah dengan video.

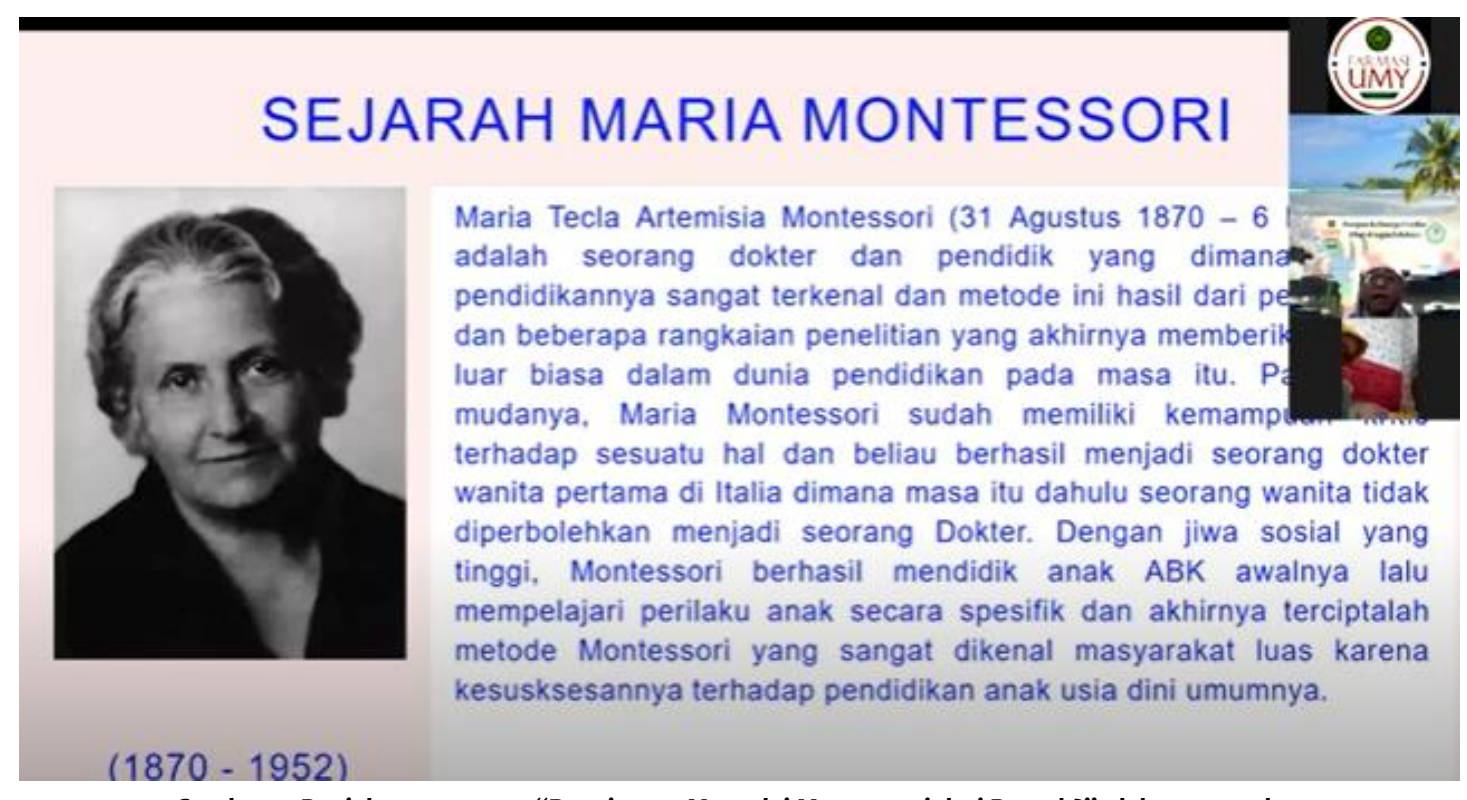

Gambar 2. Penjelasan tentang “Bagaimana Memulai Montessori dari Rumah?” oleh narasumber

Selama proses penyuluhan, peserta juga diminta untuk mengisi kuisioner. Dari 52 orang peserta, terdata 25 orang memberikan jawaban lengkap sehingga jumlah tersebut yang digunakan sebagai data pengabdian masyarakat kali ini. Dari 25 orang, didapatkan hasil bahwa:

1. Pengetahuan mengenai dagusibu

Hasil kuisioner menunjukkan $88 \%$ mengakui bahwa sebelum penyuluhan pernah mendengar istilah dagusibu, sedangkan $12 \%$ lain belum pernah. Hal ini menunjukkan perlu diadakannya penyegaran program dagusibu di kalangan sekolah-sekolah usia dini. Dengan demikian, kesadaran masyarakat, terutama orang tua/ wali murid, terhadap pengelolaan obat lebih meningkat.

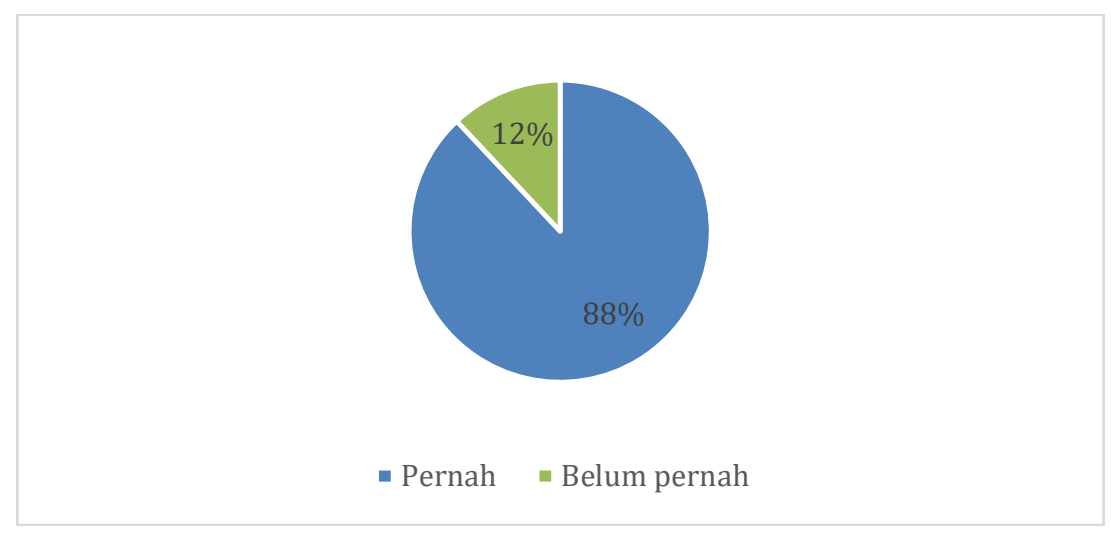


2. Pembelian obat yang tepat

Hasil menunjukkan bahwa sebanyak $76 \%$ peserta membeli obat selalu di apotek, sedangkan 24\% lainnya membeli obat di apotek dan lokasi lain, seperti supermarket, minimarket, toko obat berizin, rumah sakit dan puskesmas. Lokasi pembelian obat akan mendukung diterimanya obat dengan benar/ tidak. Lokasi yang berizin seperti apotek, rumah sakit, toko obat berizin, dan puskesmas telah memenuhi syarat keamanan lokasi. Selain itu, hal tersebut akan memudahkan pasien untuk melakukan konsultasi obat secara langsung dengan apoteker di tempat.

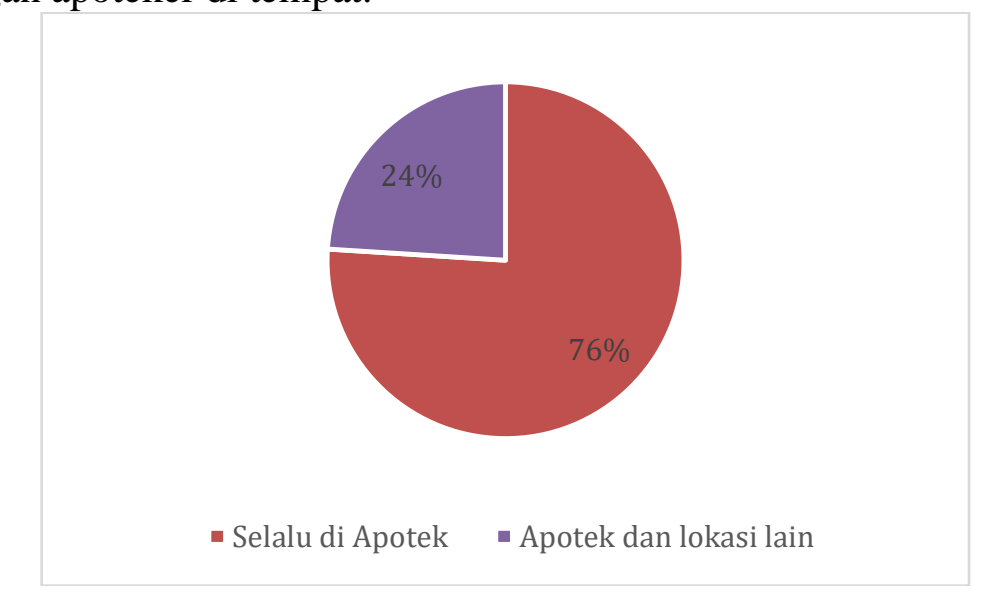

3. Informasi penggunaan obat

Hasil menunjukkan bahwa sebanyak $60 \%$ peserta menggunakan obat sesuai list ketentuan penggunaan obat dengan lengkap, sementara $40 \%$ lain tidak menjawab dengan lengkap. Hal ini menggambarkan bahwa orang tua/ wali murid TK Al Fatah telah mengetahui ketentuan penggunaan obat walaupun belum $100 \%$ mengetahuinya dengan lengkap. Ketentuan penggunaan obat secara lengkap perlu diketahui untuk memudahkan dan membantu dalam penggunaan obat.

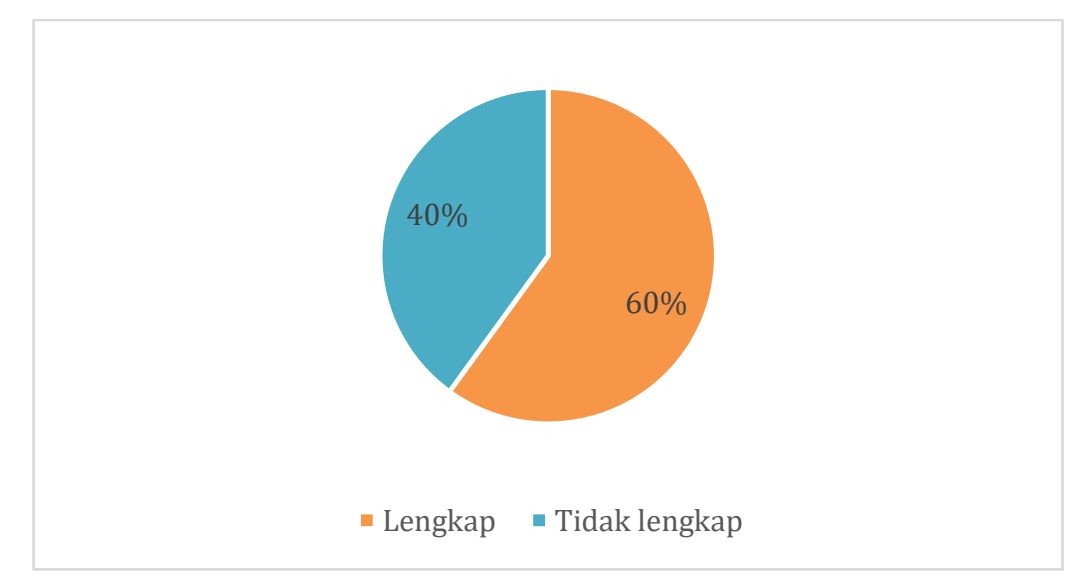

4. Pengetahuan tentang kondisi yang dapat merusak obat

Sebanyak $96 \%$ peserta menjawab benar, yakni bahwa jika obat terkena sinar matahari langsung, udara lembab, suhu ekstrim dan goncangan fisik, obat akan cepat rusak, sedangkan $4 \%$ menjawab salah. Hal ini menandakan bahwa masih terdapat orang tua/ wali di TK Al Fatah yang belum mengetahui bahwa suhu, kelembapan, dan gonjangan fisik dapat memengaruhi kualitas dan stabilitas obat. 


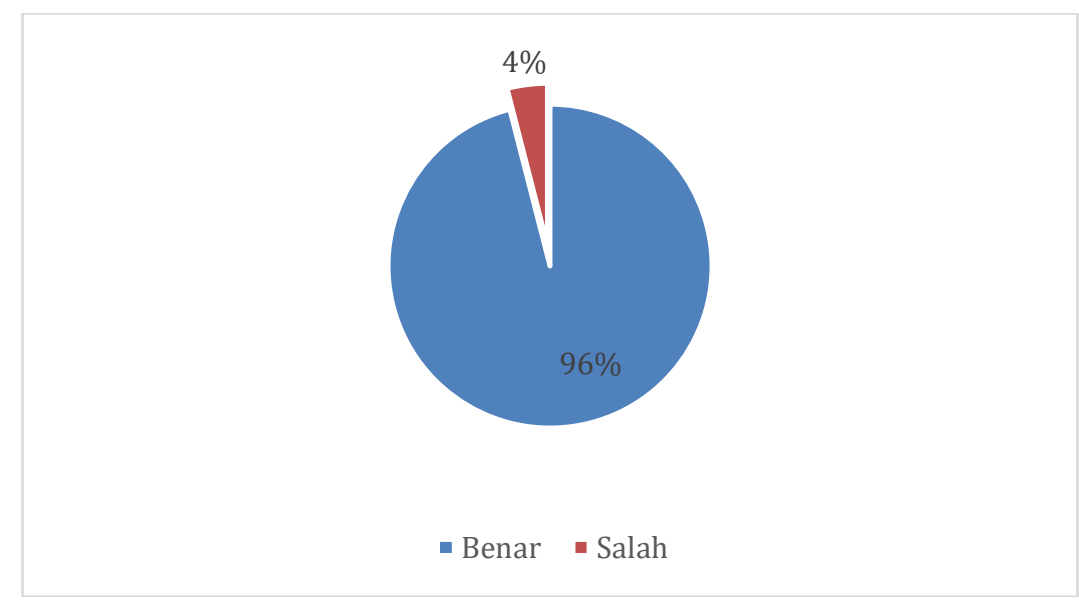

5. Pengenalan pengelolaan obat bagi anak di rumah

Dalam keluarga, sebanyak $92 \%$ peserta mengajarkan anak untuk mengelola obat, sedangkan $8 \%$ tidak mengajarkan anak tentang pengelolaan obat di rumah. Informasi ini menunjukkan tingkat kesadaran orang tua dalam menerapkan pengelolaan obat di rumah kepada anak.

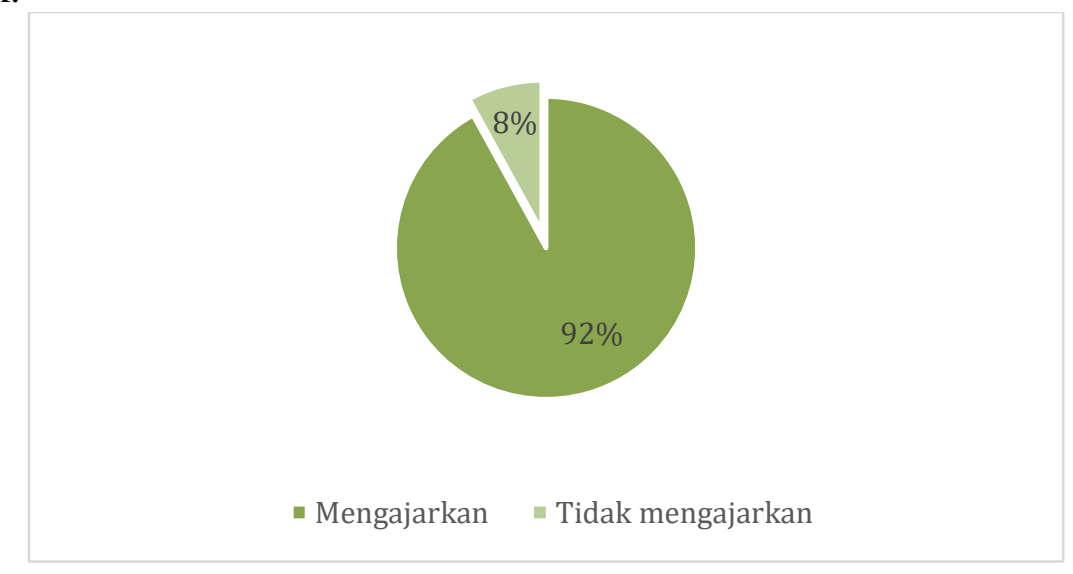

\section{Simpulan}

1. Wali murid TK Al Fatah telah mendapatkan informasi mengenai dagusibu dengan baik.

2. Wali murid TK Al Fatah telah memulai mengajarkan pengelolaan obat dengan baik pada anak usia dini di lingkungan keluarga.

3. Metode Montessori belum banyak dikenal secara detail oleh wali murid TK Al Fatah Sedan.

\section{Ucapan Terima Kasih}

Terima kasih diberikan kepada Lembaga Penelitian, Publikasi dan Pengabdian Masyarakat Universitas Muhammadiyah Yogyakarta atas pendanaan program ini. Program Pembelajaran Pemberdayaan Masyarakat ini terselenggara atas hibah dana LP3M dengan nomor: 031/PEN-LP3M/I/2020 tentang Penerima Hibah Pengabdian kepada Masyarakat Program Peningkatan Tri Darma Perguruan Tinggi Universitas Muhammadiyah Yogyakarta Tahun Akademik 2019/2020. Terima kasih juga diberikan kepada tim Edutoys dan pihak mitra TK Al Fatah Sedan atas dukungan dan kerjasamanya dalam program Pembelajaran Pemberdayaan Masyarakat (PPM) ini. 


\section{Daftar Pustaka}

Kemendikbud. (2019). Data Referensi Kementrian Pendidikan dan Kebudayaan, Profil Satuan Lembaga TK Al Fatah. Dikutip 31 Desember 2019 dari https://referensi.data.kemdikbud.go.id/tabs.php?npsn=20407901.

Direktur Bina Obat dan Publik dan Perbekalan Kesehatan. (2007). Buku Pedoman Pengelolaan Obat Publik dan Perbekalan Kesehatan di daerah perbatasan. Jakarta.

Kusumo, E.L. (2016). Montessori di Rumah: 55 Kegiatan Keterampilan Hidup. Jakarta: Erlangga.

Masyrofah. (2017). Model Pembelajaran Montessori Anak Usia Dini. Jurnal Pendidikan Anak Usia Dini. Vol 2: No.2.

PP IAI. (2014). Pedoman Pelaksanaan Gerakan Keluarga Sadar Obat Dikutip 25 Oktober 2020 dari https://iaisingkawangbengkayang.files.wordpress.com/2015/05/pedomanpelaksanaan-gkso.pdf. 